\title{
P02.03. Decreased medication use and cost savings in inpatient oncology through a yoga- based integrative medicine approach
}

\author{
J Friedman*, B Kligler, P Hommel, W Merrell \\ From International Research Congress on Integrative Medicine and Health 2012 \\ Portland, Oregon, USA. 15-18 May 2012
}

\section{Purpose}

The Urban Zen (UZ) Initiative at Beth Israel Medical Center was a pilot project evaluating the impact of a multi-faceted "optimal healing environment" intervention on quality of life and cost outcomes for inpatients on a medical oncology floor. Little research exists on the question of potential cost savings. This poster presents a summary of our findings on cost outcomes from this Initiative.

\section{Methods}

The UZ intervention included: (1) remodeling physical space; (2) holistic nursing techniques training for the nursing staff; (3) yoga therapists on the unit to work with patients using breathing and yoga techniques; (4) "patient navigator"; and (5) audiovisuals demonstrating yoga and relaxation techniques for patients to use in bed. We compared a control group admitted prior to UZ implementation to a treatment group of patients admitted after the intervention was implemented. Inclusion criteria were age 18-85, Karnofsky score $\geq 60$, life expectancy $\geq 6$ months, and English-speaking.

\section{Results}

UZ group had lower mean medication costs. Total medication costs were significantly higher for the baseline group (\$889) versus the UZ group (\$420) for a cost savings on average of $\$ 469$ per patient. Significant differences in favor of the UZ group were seen with regard to antinausea medications and anti-anxiety medications.

\footnotetext{
Beth Israel Medical Center, Department of Integrative Medicine, New York
} City, USA

\section{and take full advantage of:}

- Convenient online submission

- Thorough peer review

- No space constraints or color figure charges

- Immediate publication on acceptance

- Inclusion in PubMed, CAS, Scopus and Google Scholar

- Research which is freely available for redistribution 